\title{
Influence of external and internal cooling at solidification on strength of brittle duralumin in compression
}

\author{
Oleksandr Semko ${ }^{1}$, Oleksii Fenko ${ }^{1}$, Anton Hasenko ${ }^{1}$, Olha Harkava ${ }^{1, *}$, and Volodymyr \\ Kyrychenko ${ }^{1}$ \\ ${ }^{1}$ Poltava National Technical Yuri Kondratyuk University, Department of Reinforced Concrete and \\ Masonry Structures and Strength of Materials, 24, Pershotravneva Avenue, Poltava, 36011, Ukraine
}

\begin{abstract}
The causes of the occurrence and influence of inherent stresses, unevenly distributed across the cross section, on the strength of materials are analyzed. Methods of creating artificial distribution of inherent stresses with opposite signs in comparison with the usual distribution obtained with natural solidification of the material are given. The sequence of an experiment on cylindrical specimens made of epoxy resin and brittle silicate aluminum alloy in creating distributions of inherent stresses with opposite signs is described. The results of experimental tests of the influence of inherent stresses unevenly distributed across the cross section, on the strength of the epoxy resin and of the fragile silicate aluminum alloy with compression are given. Quantitative characteristics of the influence of unevenly distributed inherent stresses on the strength of materials under compression are obtained. The reasons of the influence of inherent stresses on the strength of materials under compression are analyzed and grounded.
\end{abstract}

\section{Introduction}

The detection of places with the highest stresses in elements of the structures has always been a topical issue in optimizing the design schemes of buildings. The sequence of the destruction of samples under the action of longitudinal force is well known: destruction begins with the surface layers of the sample in compressive tests, and the inside layers break up first in the case of tensile tests [1]. Such a sequence of destruction can be explained by the presence of irregularly distributed inherent stresses in the cross-section.

\subsection{Review of well-known publications and researches}

Details of machines, mechanisms or other structural elements can be made of metal castings. Cooling of such castings starts from the outside during solidification under normal conditions. The temperature of the inside layers exceeds the temperature of the surface layers in this process [2]. After reaching the ambient temperature, the surface layers stop

\footnotetext{
*Corresponding author: author@email.org
} 
shortening due to a decrease in temperature. Thus, they prevent the reduction of the inside layers, the temperature of which is higher. When the temperature is aligned in the cross section due to the final cooling of the casting, the surface layers will be compressed, and the inside will be tensioned. The stresses fluctuate smoothly from the surface of the sample to the core (the inside part), trying to deplan the section (they are called deplanation stresses). The above-mentioned deplanation stresses, in addition to the case during the cooling of metallic castings in their solidification, may occur in the concrete cross section in uneven shrinkage [3-5], which influences its work under biaxial bending $[6,7]$ and in reduction $[8,9]$. The same picture is observed in hammered or rolled elements: the surface layers undergo an intense deformation, which causes the described distribution of inherent stresses after cooling. The deplanation stresses will increase with increasing sample sizes, (due to a greater difference in the temperature of the inside and surface layers of the casting), which must also affect the scale effect $[10,11]$.

\subsection{Highlight a previously unresolved issue}

During the loading of the sample along the axis by the compressive force, the stress field caused by mechanical loading will be imposed on the distribution of its inherent deplanation stresses obtained during solidification. Thus, the stresses in the surface layers and the stress caused by the mechanical load are added (since they are like-sign) when testing samples on compression. Therefore, the destruction in compression begins with the surface layers. At the same time, the stresses in the inside layers are smaller than in the surface (in the inside layers the stresses are opposite sign). The surface layers begin to collapse, after which the destruction spreads to the middle of the sample.

During the tensile test, the opposite effect occurs, which is also due to imposition of stress distributions (inherent and caused by external load). As with compression, the stresses will be added with only the difference, that now the inherent and the mechanical stresses in the core of the cross section are like-sign. The stresses in the surface layers will be subtracted, because the inherent and the mechanical stresses are opposite sign. Thus, the destruction begins with the surface layers of the sample and extends outward.

\subsection{Research objective}

The purpose of the study is to confirm experimentally the theoretical conclusions about the influence of the distributions of the inherent deplanation stresses caused by the conditions of solidification during cooling, on the strength of the samples under compression.

Achievement of the set goal is possible by creating an artificial distribution of the inherent (deplanation) stresses with opposite signs compared to the usual distribution obtained with the natural solidification of the material. When artificially creating a distribution of the deplanation stresses, reversed to the natural distribution, dangerous stresses will first appear in the core of the cross-section in compressing tests. However, the sample will better resist fracture due to the casing effect created by the less stressed surface layers. Thus, the effect of increasing the strength can be achieved in compression tests through the created field of inherent stresses. It should be noted that this effect could not be achieved in tensile tests. When creating an inverse natural distribution of the inherent stresses, the sequence of destruction of the sample will be from the surface layers to the core, and strength increase cannot be obtained. 


\section{Main material and results}

\subsection{Experiments on samples of epoxy resin}

Experiments on samples of epoxy resin [1] were carried out for the preliminary confirmation of the conclusions made regarding the imposition of stress fields. Two series of samples were manufactured and tested for the purpose of the work (see Table 1). Each series of samples was consisted of two groups.

Table 1. Nomenclature of epoxy resin experimental samples.

\begin{tabular}{|c|c|c|c|c|c|}
\hline $\begin{array}{l}\text { Series } \\
\text { sample } \\
\text { number }\end{array}$ & $\begin{array}{l}\text { Series name } \\
\text { (sample } \\
\text { material) }\end{array}$ & $\begin{array}{l}\text { Purpose of } \\
\text { research of } \\
\text { series of } \\
\text { samples }\end{array}$ & $\begin{array}{l}\text { Sample } \\
\text { group code }\end{array}$ & \multicolumn{2}{|c|}{$\begin{array}{l}\text { Group name (the essence of the } \\
\text { manufacturing) }\end{array}$} \\
\hline \multirow{4}{*}{1} & \multirow{4}{*}{$\begin{array}{l}\text { Three-layer } \\
\text { cylinders } \\
\text { made of } \\
\text { epoxy resin }\end{array}$} & \multirow{4}{*}{$\begin{array}{l}\text { Preliminary } \\
\text { detection of the } \\
\text { investigated } \\
\text { effect }\end{array}$} & LISE & \multirow{2}{*}{$\begin{array}{l}\text { Samples with } \\
\text { previous chain } \\
\text { loading of layers } \\
\text { during } \\
\text { manufacturing: }\end{array}$} & $\begin{array}{l}\text { from inside } \\
\text { to outside }\end{array}$ \\
\hline & & & LSIE & & $\begin{array}{l}\text { from outside } \\
\text { to inside }\end{array}$ \\
\hline & & & ISE & \multirow{2}{*}{$\begin{array}{l}\text { Control unloaded } \\
\text { samples: }\end{array}$} & $\begin{array}{l}\text { made from } \\
\text { inside to } \\
\text { outside }\end{array}$ \\
\hline & & & SIE & & $\begin{array}{l}\text { made from } \\
\text { outside to } \\
\text { inside }\end{array}$ \\
\hline \multirow[b]{2}{*}{2} & \multirow{2}{*}{$\begin{array}{l}\text { Castings } \\
\text { from } \\
\text { duralumin } \\
\text { (brittle } \\
\text { silicate } \\
\text { aluminum } \\
\text { alloy A-12) }\end{array}$} & \multirow{2}{*}{$\begin{array}{l}\text { Detection of the } \\
\text { influence of } \\
\text { internal and } \\
\text { external cooling } \\
\text { on compressive } \\
\text { strength }\end{array}$} & ISD & \multicolumn{2}{|c|}{$\begin{array}{c}\text { Samples of artificial solidification } \\
\text { (cooling from the inside layers to } \\
\text { the outside) }\end{array}$} \\
\hline & & & SID & \multicolumn{2}{|c|}{$\begin{array}{c}\text { Samples of natural solidification } \\
\text { (cooling of the outside layers to } \\
\text { the inside) }\end{array}$} \\
\hline
\end{tabular}

Cylindrical specimens with a diameter of $30 \mathrm{~mm}$ and a height of $60 \mathrm{~mm}$ were made of epoxy resin in three stages. The sequence of the production of samples of LISE group (see Table 1, series 1) is from the inside layers to the outside ones, with the interval between the casting of the layers of 10 days (after the set of sufficient strength of layers). The first inside layer, which cured for 10 days, was loaded with the compressive force $q_{1}$ and covered around by the next layer (Fig. 1, a). After 10 days, both layers (inside and middle) were loaded with more force $q_{2}$. After that, the last surface layer was poured. Then the samples gained strength for 10 days, after which they were tested in compression.

Samples of the LSIE group (see Table 1, series 1) were made in the reverse order (Fig. 1, b). The surface layer was made the first. It was loaded by compressive force $q_{1}$ after 10 days and the middle layer was poured. Both layers were loaded with force $q_{2}$ after hardening and the last inside layer was poured.

The field of inherent stresses was created after unloading of the LISE samples, in which the inside part of the sample was compressed and the outside was tensioned. There was the field of inherent stresses with opposite signs in the samples of the LSIE: the surface layers were compressed and the inside were tensioned. Thus, with the same strength of the material of different layers, the effect of their inherent stresses on samples of LSIE is close to the distribution of stresses with natural hardening of casting, and in samples of LISE the effect is opposite to the natural (artificially created distribution). Therefore, a greater 
strength of LISE samples was expected. It should be noted that the strength of the layers was different due to different periods of their hardening in the manufacturing.

LISE

a)

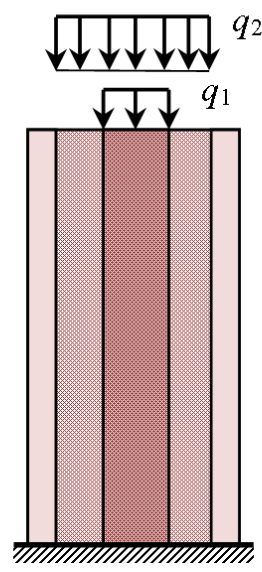

LSIE

b)

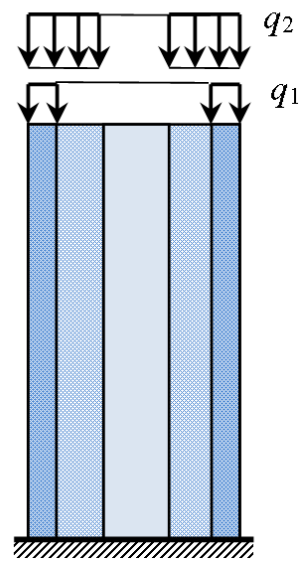

Fig. 1. Sequence of solidification and loading the epoxy resin specimens during manufacturing: a) LISE group (from inside to outside); b) LSIE group (from outside to inside).

In addition, for assessing the effect of the resin strength difference in layers ISE and SIE samples were made at the same time with LISE and LSIE, which were not loaded in the manufacture (see Table 1, Series 1). The results of the experiment are shown in Figure 2.

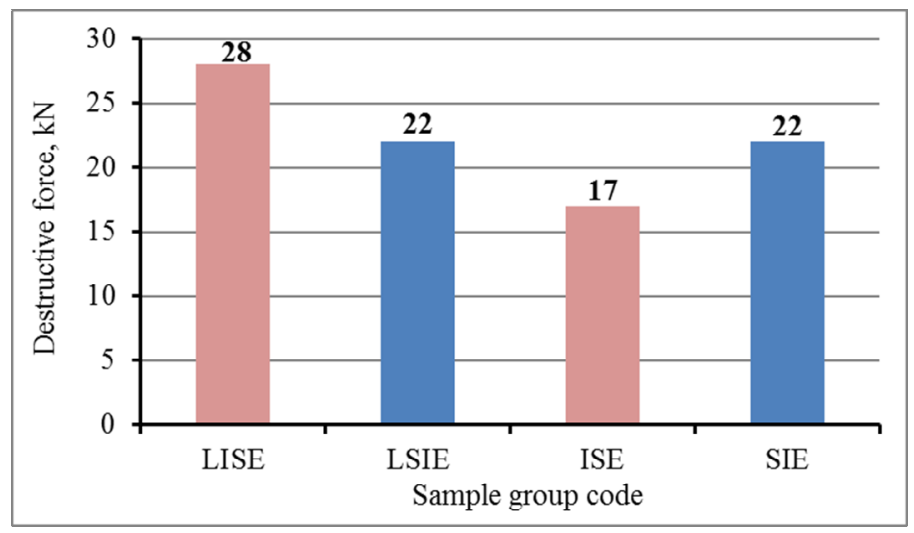

Fig. 2. Results of the first series samples tests.

As it can be seen from Fig. 2, the results of the experiment confirm the previous conclusions. LISE examples were stronger than LSIE, whereas ISE samples had less strength than SIE. This suggests that the effect of the inherent (deploating) stresses blocked the effect of the material strength difference in the layers of samples.

The disadvantage of the experiments with samples of the first series, made of epoxy resin, was that their own stresses were distributed gradually across the cross section. Some errors in the results of experiments were due to the epoxy resin was an aging material, and in different layers there were different terms of hardening of the resin due to the technology of making the samples. It is logical to conduct experiments on non-aging material to eliminate these shortcomings. At the same time, the samples should be manufactured at one casting. 


\subsection{Experiments on samples of duralumin}

The planned second series of samples eliminates the disadvantages of the first series. The experiments on the determination of the influence on the strength of the unevenly distributed inherent stresses due to different cooling sequences were carried out on duralumin specimens (fragile silicate aluminium alloy A-12) under compression. The height of the samples is $60 \mathrm{~mm}$, the diameter is $30 \mathrm{~mm}$. Samples should be made with the artificial distribution of the inherent stresses (Fig. 3, b) of the opposite sign to the field of the inherent stresses that occurs in natural hardening (Fig. 3, a) to prove the influence of the inherent stresses on the strength of material. That is, the surface layers should be tensioned, and the internal ones should be compressed. This distribution of stresses can be achieved by a reciprocal cooling of the castings during their hardening, that is, starting from the inside.

SID

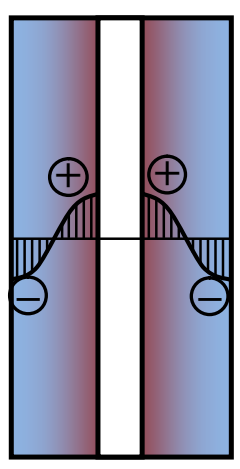

ISD

b)

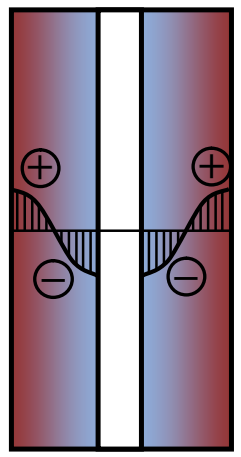

Fig. 3. Distribution of the inherent stresses when cooling the second series samples: a) starting from the surface layers (SID); b) from the inside layers (ISD).

The samples in each test lot were cast out of one fusion to prevent inaccuracies in the obtained results and increase the reliability. SID samples of "natural" hardening were cast in the steel moulding boxes and cooled from the surface layers. In the steel moulding boxes (of the same size as the previous ones), designed for the production of ISD samples, a steel tube with a diameter of $6 \mathrm{~mm}$ was mounted in the centre (see Fig. 4). The moulding boxes were in cylindrical asbestos thermal insulators. An electric heating helix was mounted inside of the heat insulators.

In order to ensure the objectivity of the results of the experiment, the succession of duralumin casting in each test lot was consistently changed: in some test lots, samples of natural hardening were casted first, in other test lots, on the contrary: the moulding boxes of the "opposite" stress field were poured first. The height of the castings was one and a half times bigger than the planned height of the samples to ensure the prevention of the possible ingress of oxidized metal into samples.

The order of samples production with the opposite artificial field of inherent stresses was as follows. An electric spiral and water supply were included before the filling of the duralumin. The moulding box was heated to the melting point of duralumin. When the duralumin was casted, the lid in the thermal insulation was opened for several seconds and the electric spiral was switched off. Water was fed until complete hardening and considerable cooling of the sample. 

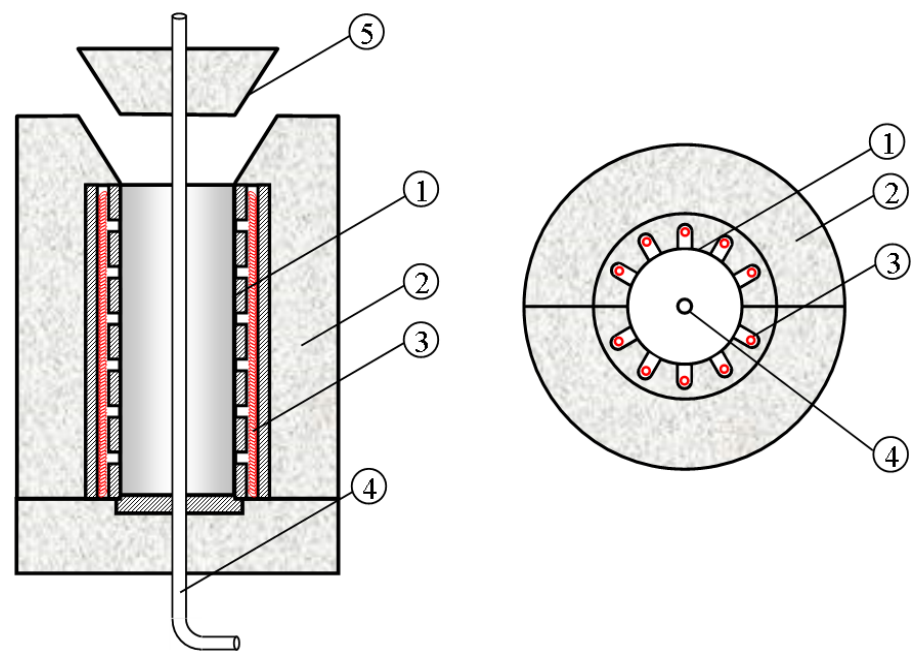

Fig. 4. Thermo-insulated moulding box for samples with "opposite" distribution of the inherent stresses: 1 - steel form; 2 - asbestos thermal insulation; 3 - electric spiral; 4 - water supply pipe; 5 - thermal insulation cover.

In order to ensure the objectivity of the results of the experiment, the succession of duralumin casting in each test lot was consistently changed: in some test lots, samples of natural hardening were casted first, in other test lots, on the contrary: the moulding boxes of the "opposite" stress field were poured first. The height of the castings was one and a half times bigger than the planned height of the samples to ensure the prevention of the possible ingress of oxidized metal into samples. The order of samples production with the opposite artificial field of inherent stresses was as follows. An electric spiral and water supply were included before the filling of the duralumin. The form was heated to the melting point of duralumin. When the duralumin was casted, the lid in the thermal insulation was opened for several seconds and the electric spiral was switched off. Water was fed until complete hardening and considerable cooling of the sample.

The effect of versatile cooling (internal and external) was detected before experimental testing: in the SID samples, the inside part of the specimen was concave inside the sample, and in the ISD samples it was convex outward (see Fig. 5). This indicates the accumulation of the inherent stresses in the casting material during its cooling.

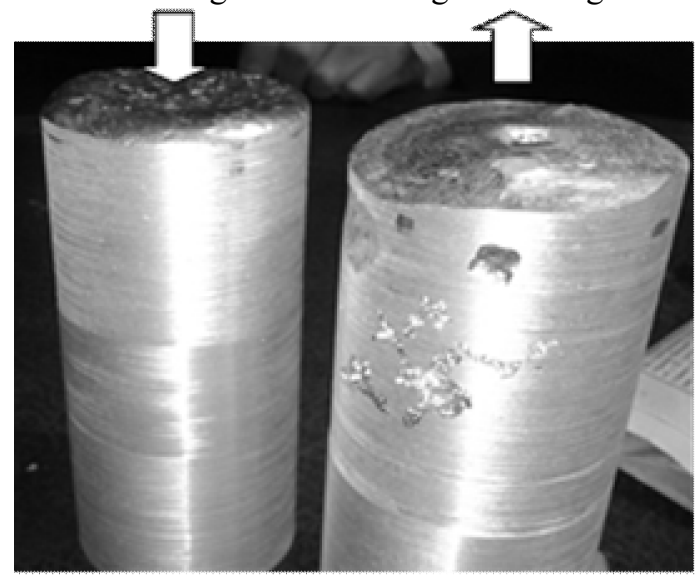

Fig. 5. The second series samples after casting and lathing: on the left - a SID sample, on the right an ISD sample. 
The samples were lathed to the planned sizes after cooling. The upper part $(30 \mathrm{~mm}$ high) of the work piece was cut off. The opening diameter $6 \mathrm{~mm}$ was turned along the axis in the SID samples. Thus, all geometric characteristics were the same in the samples.

The nature of the destruction of samples completely confirmed the fragility of the tested duralumin during the tests (see Fig. 6). The results of the tests are shown in Figure 7. Comparison of the strength of the tested samples of the two groups are given in Table 2.
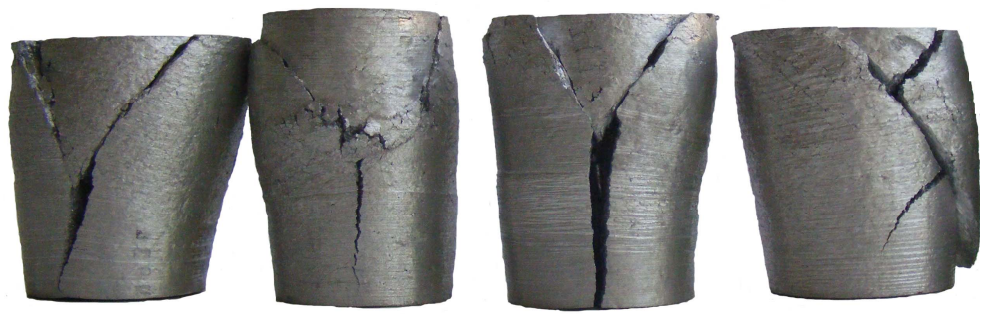

Fig. 6. General view of the second series samples after the test.

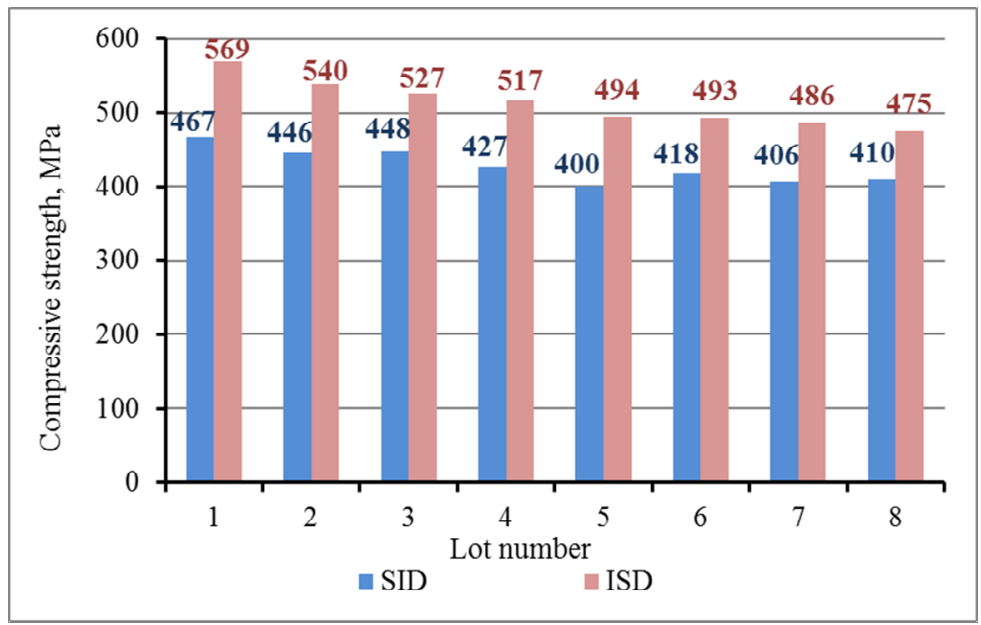

Fig. 7. Results of the second series samples tests.

Table 2. Comparison of duralumin specimens' strength with opposite signs of the inherent stresses distribution.

\begin{tabular}{|c|c|c|c|c|}
\hline \multirow{2}{*}{$\begin{array}{c}\text { Casting } \\
\text { lot number }\end{array}$} & \multicolumn{2}{|c|}{ Strength, MPa } & \multicolumn{2}{c|}{ Strength difference } \\
\cline { 2 - 5 } & SID & ISD & MPa & $\%$ \\
\hline 1 & 467 & 569 & 102 & 21.8 \\
\hline 2 & 446 & 540 & 94 & 21.1 \\
\hline 3 & 448 & 527 & 79 & 17.6 \\
\hline 4 & 427 & 517 & 90 & 21.1 \\
\hline 5 & 400 & 494 & 94 & 23.5 \\
\hline 6 & 418 & 493 & 75 & 17.9 \\
\hline 7 & 406 & 486 & 80 & 19.7 \\
\hline 8 & 410 & 475 & 65 & 15.9 \\
\hline
\end{tabular}




\section{Conclusions}

Experiments confirmed preliminary conclusions about the influence of the unevenly distributed across the cross section inherent stresses on the strength of the material. The difference in strength caused by opposite distributions of the inherent stresses due to different cooling sequences is about $20 \%$. Thus, each field of the inherent stress leads to a change in strength by an average of $10 \%$.

Some differences in the strength of samples in different castings can be explained by the fact that the samples after the tests were melting and used for the production of new samples, and the repeated melting led to some changes in the properties of duralumin.

\section{References}

1. YA.B. Fridman, Mehanicheskie svoystva metallov. CHast 2. Mehanicheskie ispyitaniya. Konstruktsionnaya prochnost (1972)

2. A.N. Krutilin, P.E. Luschik, A.A. Andrits, Lite i metallurgiya, 4, 10 (2014)

3. O.G. Fenko, O.A. Krupchenko, I.A. Yurko, Acad. journal industrial machine building, civil eng., 2(47), 155 (2016)

4. X. Chen, W. Huang, J. Zhou, Indian Journal of Eng. and Materials Sc., 19, 427 (2012)

5. H. Hotta, K. Takiguchi, Nucl. Eng. Des., 156(6), 218 (1995)

6. A.M. Pavlikov Neliniina model napruzheno-deformovanoho stanu kosozavantazhenykh zalizobetonnykh elementiv u zakrytychnii stadii (2007)

7. A.M. Pavlikov, D.V. Kochkarov, Naukovo-tekhnichnyi, vyrobnychyi ta informatsiinoanalitychnyi zhurnal "Nauka ta budivnytstvo", 3, 22 (2017)

8. D.A. Yermolenko, Stroytelstvo, materyalovedenye, mashynostroenye: Sb. nauch. Trudov, 61, 172 (2011)

9. S.A. Hudz, Stalezalizobetonni konstruktsii: doslidzhennia, proektuvannia, budivnytstvo, ekspluatatsiia: Zb. nauk. Statei, 12, 76 (2016)

10. O.G. Fenko, Zb. nauk. prats (haluzeve mashynobuduvannia, budivnytstvo), 2(44), 86 (2015)

11. Z.P. Bazant, Jia-Liang Le, Sadhana (Indian Acad. of Sc.), 37(1), 1731 (2012) 